\title{
Pancreas Procurement and Preservation for Islet Transplantation: Personal Considerations
}

\author{
Hirofumi Noguchi \\ Department of Gastroenterological Surgery, Okayama University Graduate School of Medicine, \\ Dentistry and Pharmaceutical Sciences, Okayama 700-8558, Japan \\ Correspondence should be addressed to Hirofumi Noguchi, noguch-h@cc.okayama-u.ac.jp
}

Received 18 May 2011; Revised 29 June 2011; Accepted 13 July 2011

Academic Editor: Antonello Pileggi

Copyright (C) 2011 Hirofumi Noguchi. This is an open access article distributed under the Creative Commons Attribution License, which permits unrestricted use, distribution, and reproduction in any medium, provided the original work is properly cited.

Pancreatic islet transplantation is a promising option for the treatment of type 1 diabetic patients. After the successful demonstration of the Edmonton protocol, islet transplantation has advanced significantly on several fronts, including improved pancreas procurement and preservation systems. Since we frequently use pancreata from donors after cardiac death in Japan,we have applied the in situ regional organ cooling system for pancreas procurement to reduce the warm ischemic time. To reduce the apoptosis of pancreatic tissue during cold preservation, we have applied the ductal injection of preservation solution. For pancreas preservation, we use modified Kyoto solution, which is advantageous at trypsin inhibition and less collagenase inhibition. In this paper, we show pancreas procurement and preservation in our group for islet transplantation.

\section{Introduction}

Diabetes mellitus is a devastating disease, and over 200 million people are affected worldwide, thus representing about $6 \%$ of the world population. Type 1 diabetes results from the autoimmune-mediated destruction of insulinsecreting $\beta$ cells in the islets of Langerhans of the pancreas. Pancreatic islet transplantation represents a viable option for the treatment of patients with unstable type 1 diabetes mellitus with frequent severe hypoglycemia and hypoglycemia unawareness $[1,2]$. Recent advances in islet transplantation, including the utilization of donors after cardiac death (DCD) [3-6], single-donor islet transplantation [7-10], and livingdonor islet transplantation [11], were based on advanced pancreas transport systems $[9,12,13]$, improved islet isolation methods [14-17], enhanced islet engraftment [18-21], and revised immunosuppressant protocols $[6,14,22]$. One of the most important issues affecting islet transplantation is concerned with donor quality [23]. Several critical donor factors have been identified, including donor age, body mass index (BMI), cause of death, usage of vasopressor, hypotensive episode, length of hospitalization, blood glucose levels, transaminases level, creatinine levels, cold preservation time, and procurement team [23-26]. Therefore, effective pancreas procurement and preservation are important for successful islet isolation and transplantation. In this paper, the current advances in pancreas procurement and preservation for islet transplantation in our group are described.

\section{Pancreas Procurement}

Pancreata from donors with brain death (DBD) are procured using a standardized technique to minimize warm ischemia. A preservation solution, such as the University of Wisconsin (UW) solution, is used for in situ perfusion of the donor. The human pancreas is excised immediately after the liver and before the kidneys. The first and fourth portions of the duodenum are first divided with a $55 \mathrm{~mm}$ linear cutter. The attachment between the retroperitoneal portion and the body of the pancreas is then dissected toward the spleen. The superior surface of the pancreas is divided toward the spleen, and the short gastric arteries and vein are dissected until the stomach is separated from the spleen. The pancreas is then rapidly excised en bloc together with the spleen. The spleen and duodenum are subsequently removed on a back table, and a cannula is inserted into the main pancreatic duct.

Currently, only a few clinical studies have reported that islet transplantation from DCD is possible to treat type 1 diabetes [27, 28]. Vasopressors are used for most 


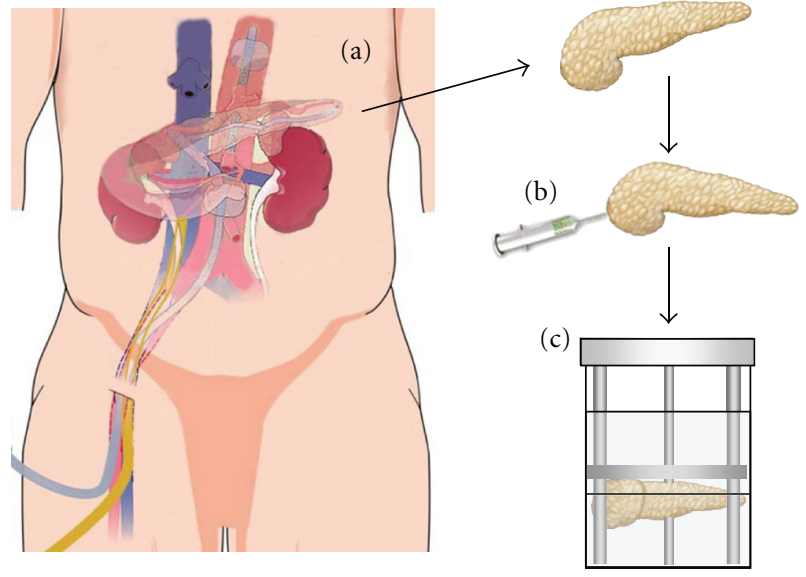

Figure 1: Pancreas procurement and preservation for islet transplantation. (a) In situ regional cooling system to DCD pancreata. (b) Ductal injection of preservation solution. (c) Pancreas preservation by MK solution/PFC two-layer method.

DCDs, and they tend to have hypotensive episodes, long term hospitalization, and high levels of blood glucose, transaminases, and creatinine which have been identified as critical factors that affect the quality of the pancreas [23-26]. Islet transplantation from DCD is particularly important for countries such as Japan, where the isolation of islets from pancreata of donors who are classified as brain-dead but whose hearts are beating is prohibited by law. We developed the novel procurement technique in collaboration with the kidney procurement team [29]. After confirmation of brain death, a double-balloon catheter is inserted to prevent ischemic damage to the human pancreas by using an in situ regional organ cooling (ISRC) system that was originally developed for procurement of the kidney [30]. Before cardiac arrest, a tip of the double-balloon catheter is placed above the celiac axis in the aorta via the femoral artery and only a few centimeters above the location used for an ordinary nephrectomy for procurement from a DCD. A venous catheter is also placed in the inferior vena cava via the femoral vein for drainage of the perfusate and blood. ISRC for the pancreas and kidney (ISRC-PK) is achieved by pump or drip infusion (drip speed $20 \mathrm{~mL} / \mathrm{min}$ ) of a hypothermic lactated ringer solution beginning immediately after cardiac arrest and then continuing until the end of the nephrectomy and pancreatectomy. After laparotomy, the lesser sac is opened by dividing the gastrocolic and gastrohepatic ligaments to determine whether the pancreas has uniform perfusion efficacy by means of ISRC-PK. Perfusion of the pancreas is evaluated by the uniform color change of the pancreas and the coldness of the pancreas surface after laparotomy. After a visual check of the pancreas, $500 \mathrm{~mL}$ of sterile crushed ice is placed on it to avoid warm ischemic injury and then the pancreas is harvested (Figure 1(a)) [29].

The ISRC system was originally developed for the procurement of the kidney [30], and the only modification we made is the position of the double-balloon catheter to ensure both pancreas and kidney protection. This ISRC system reduced the warm ischemic time to only 3 minutes on average [29]. We have used lactate ringer solution instead of UW solution for perfusion. Lactate ringer solution has a low potassium concentration and low viscosity in comparison to UW solution. A low potassium concentration could prevent potassium-induced vasospasms while a low viscosity helps to induce rapid perfusion. Therefore, using lactate ringer for perfusion might be important in ISRC.

\section{Ductal Injection of Preservation Solution}

We previously developed a new method for large-scale porcine islet isolation from market-weight pigs [31], based on a report by O'Neil et al. [32]. Although some steps of the new method seemed technically inferior to the standard automated method using a Ricordi chamber, islet yield per gram for our new method was relatively higher (but not significantly so) than that for the Ricordi method [33]. It is possible that the advantage of the new method was the injection of $1.0-1.5 \mathrm{~mL} / \mathrm{g}$ pancreas of UW-D (UW solution with high $\mathrm{Na}^{+}$/low $\mathrm{K}^{+}$) solution. It was also shown that islet yields from pancreata with intraductal flush, along with collagenase prior to preservation, were superior to vascular flush [34]. We speculate that the ductal injection of a large volume of preservation solution $(1 \mathrm{~mL} / \mathrm{g}$ pancreas) may improve the islet yield. We investigated whether ductal injection (UW and modified Kyoto (MK) solution) before pancreas storage improves the islet yields in islet isolation using porcine pancreata. After obtaining the pancreas, we immediately inserted a cannula into the main pancreatic duct, infused a large amount of preservation solution ( $1 \mathrm{~mL} / \mathrm{g}$ pancreas) for ductal protection, and placed the pancreas into a preservation container (Figure 1(b)). The islet yield both before and after purification was significantly higher in the ductal injection group than in the control group. The TUNELpositive cells in the ductal injection group significantly decreased in comparison to the control group. The ductal injection of preservation solution increased the ATP level in the pancreas tissue and reduced trypsin activity during the digestion step. In a transplant model, ductal injection improved the islet graft function. These findings suggest that the ductal injection of preservation solution leads to improved outcomes for pancreatic islet transplantation [35]. Another group also showed the ductal injection of a small volume $(0.05-0.1 \mathrm{~mL} / \mathrm{g})$ of UW solution at the time of pancreas procurement to improve the islet yield and function in a rodent model [36]. Based on these data, we now use this technique for clinical islet transplantation. With this technique, we rarely see clumping or DNA release, even using DCD, and we never use DNase.

\section{Preservation Solution}

UW solution has been recognized as the gold standard solution for organ preservation. UW solution is used extensively as a cold storage solution during procurement and transport of the pancreas prior to islet isolation. However, 
UW solution has several disadvantages: it must be stored in the cold until use, and its short shelf life makes it expensive. It is also highly viscous, which may complicate the initial organ flush [37]. For islet isolation, it has been observed that UW inhibits the collagenase digestion phase of islet isolation, thus resulting in poor islet yields and islets of poor viability $[38,39]$. It has been reported that the components in UW solution found to be most inhibitory were magnesium, low $\mathrm{Na}^{+}$/high $\mathrm{K}^{+}$, hydroxyethyl starch (HES), and adenosine. Furthermore, previous reports also indicated that allopurinol in combination with either lactobionate or glutathione markedly inhibited collagenase and that the most inhibitory solution tested was a combination of three components, raffinose, glutathione, and lactobionate [39]. We evaluated the effect of MK solution for islet isolation [12]. Kyoto University developed the ET-Kyoto solution, and its effectiveness in cold lung storage has been demonstrated in clinical lung transplantation $[40,41]$. It also is effective for skin flap storage, and its clinical application is beginning in this field [42]. MK solution is a modified ET-Kyoto solution, in which ulinastatin is added. MK solution contains trehalose, gluconate, and ulinastatin as distinct components. Trehalose has a cytoprotective effect against stress, and gluconate acts as an extracellular oncotic agent, which prevents cells from swelling [44]. Ulinastatin is a trypsin inhibitor and eliminates trypsin activity during pancreas preservation [12]. Due to the chemical stability of the effective components and other ingredients, MK solution, but not UW solution, can be stored at room temperature for a long period. MK solution has high $\mathrm{Na}^{+} /$low $\mathrm{K}^{+}$, and it includes only HES at a lower concentration than UW solution, thus suggesting a lower collagenase inhibition than UW solution. It has also been shown that the $\mathrm{Na}^{+} / \mathrm{K}^{+}$ratio, adenosine, allopurinol, and glutathione are not essential for the cold storage of pancreatic digest prior to islet purification [45]. Moreover, trehalose and ulinastatin inhibit collagenase digestion less than UW solution [12]. The high potassium concentration in UW solution causes vasospasms and insulin release from pancreatic $\beta$ cells [46], and the high viscosity of UW solution may thus prevent sufficient flushing and ductal injection. In both porcine and human islet isolation, the islet yield was significantly higher in the MK group compared with the UW group $[12,47]$. These findings show that MK solution is a more effective cold-storage solution in pancreas preservation for islet isolation than UW solution.

We next compared histidine-tryptophan-ketoglutarate (HTK) solution and MK solution for islet isolation. HTK solution was originally developed for cardioplegia and is being used with increasing frequency in cardiac, renal, and hepatic transplantation $[48,49]$. The protective effect of HTK solution is based on the strong buffering capacity of histidine. This solution has a low viscosity, easy handling properties, and a relatively low cost. Some studies have demonstrated similar results between UW and HTK solutions for pancreas preservation, in not only experimental animal models $[43,50,51]$ but also clinical pancreas transplantation [52-54]. We used HTK solution with ulinastatin (modified HTK solution (M-HTK)) in this study because
MK solution includes ulinastatin. In porcine islet isolation, the islet yield after purification was significantly greater in the MK group than in the M-HTK group. The MK group had a significantly higher ATP level in the islets than in the M-HTK group. These data suggest that MK solution is better for pancreas preservation before islet isolation than M-HTK solution [55]. The M-HTK solution includes magnesium but does not include HES, adenosine, allopurinol, lactobionate, glutathione, or raffinose. There are no significant differences between the MK and M-HTK solutions regarding collagenase activity. Therefore, the different islet yields after purification are not due to differences in collagenase inhibition between these two solutions. Since a significantly higher ATP level in islets was observed in the MK group compared to the M-HTK group, the cytoprotective effect such as HES and/or trehalose might be a factor in the islet yield differences observed between the two solutions. Another group recently reported that, compared with UW solution, HTK solution has similar efficiency for preserving human pancreata for subsequent islet isolation during $<10 \mathrm{~h}$ cold ischemia time, but prolonged cold storage resulted in a reduced islet yield [56].

Recently, Celsior solution has been used as an alternative solution for organ preservation. Celsior is an extracellular solution deprived of colloid and was initially developed for heart preservation [57]. Preliminary clinical studies showed no differences between UW and Celsior for lung [58], liver [59], and kidney [60] preservation. Hubert et al. recently reported on the application of Celsior solution for in situ perfusion of the donor before human and pig islet isolation [61]. Their data showed the in situ perfusion of UW solution to be superior to Celsior solution. In contrast to UW, Celsior induced cell swelling and pancreas edema after only four hours of cold storage. The components of Celsior solution are in part similar to MK solution (a high-sodium/lowpotassium composition with comparatively low viscosity) and in part similar to UW solution (including lactobionate acid and glutathione). We next compared modified Celsior solution (Celsior solution with HES and nafamostat mesilate, HNC) and MK solution [47]. Since Celsior solution lacks HES, which is an oncotic agent and protects cell swelling, we added HES to Celsior solution in this study. We also added nafamostat mesilate, one of the trypsin inhibitors, to Celsior because one of the advantages of MK solution is trypsin inhibition by ulinastatin. Nafamostat mesilate has a higher level of trypsin inhibition than ulinastatin $[62,63]$. In human islet isolation, the islet yield after purification was significantly higher in the MK group than in the HNC group. The HNC group had a longer phase I period (digestion time), a higher volume of undigested tissue, and a higher percentage of embedded islets, thus suggesting that the solution may inhibit collagenase. However, there was no significant difference in the ATP content in the pancreata or in the attainability of posttransplant normoglycemia in diabetic nude mice between the two groups, thus suggesting that the quality of islets was similar between the two groups. These data suggest that MK solution is better for pancreas preservation before islet isolation than HNC solution (Tables 1 and 2). 
TABLE 1: Composition and other characteristics of each preserving solution.

\begin{tabular}{lccccc}
\hline & ET-K & MK & UW & HNC & M-HTK \\
\hline $\mathrm{Na}(\mathrm{mmol} / \mathrm{L})$ & 100 & 100 & 29 & 100 & 15 \\
$\mathrm{~K}(\mathrm{mmol} / \mathrm{L})$ & 43.5 & 43.5 & 125 & 15 & 10 \\
$\mathrm{Mg}(\mathrm{mmol} / \mathrm{L})$ & - & - & 5 & 13 & 4 \\
$\mathrm{Ca}(\mathrm{mmol} / \mathrm{L})$ & - & - & - & 0.25 & 0.015 \\
$\mathrm{Cl}(\mathrm{mmol} / \mathrm{L})$ & - & - & - & 41 & 50 \\
Gluconate $(\mathrm{mmol} / \mathrm{L})$ & 100 & 100 & - & - & - \\
Phosphate $(\mathrm{mmol} / \mathrm{L})$ & 25 & 25 & 25 & - & - \\
Sulfate $(\mathrm{mmol} / \mathrm{L})$ & - & - & 5 & - & - \\
Lactobionate $(\mathrm{mmol} / \mathrm{L})$ & - & - & 100 & 80 & - \\
Raffinose $(\mathrm{mmol} / \mathrm{L})$ & - & - & 30 & - & - \\
Trehalose $(\mathrm{mmol} / \mathrm{L})$ & 120 & 120 & - & - & - \\
Adenosine $(\mathrm{mmol} / \mathrm{L})$ & - & - & 5 & - & - \\
Alloprinol $(\mathrm{mmol} / \mathrm{L})$ & - & - & 1 & - & - \\
Glutathione $(\mathrm{mmol} / \mathrm{L})$ & - & - & 3 & 3 & - \\
HES $(\mathrm{g} / \mathrm{L})$ & 30 & 30 & 50 & 30 & - \\
Ulinastatin $(\times 103 \mathrm{U} / \mathrm{L})$ & - & 100 & - & - & 100 \\
Nafamostat mesilate $(\mathrm{mg} / \mathrm{L})$ & - & - & - & 20 & - \\
Histidine $(\mathrm{mmol} / \mathrm{L})$ & - & - & - & 30 & 198 \\
Mannitol $(\mathrm{mmol} / \mathrm{L})$ & - & - & - & 60 & 30 \\
$\alpha$-ketoglutarate $(\mathrm{mmol} / \mathrm{L})$ & - & - & - & - & 1 \\
Tryptophan $(\mathrm{mmol} / \mathrm{L})$ & - & - & - & - & 2 \\
Glutamic acid $(\mathrm{mmol} / \mathrm{L})$ & - & - & - & 20 & - \\
Osmolality $(\mathrm{mOsm})$ & 366 & 366 & 320 & 355 & 310 \\
\hline
\end{tabular}

HES: hydroxyethyl starch; ROS: reactive oxygen species; ET-K: ET-Kyoto solution; MK: modified ET-Kyoto solution; UW: University of Wisconsin solution; HNC: Celsior solution with HES and nafamostat mesilate; MHTK: modified histidine-tryptophan-ketoglutarate solution.

TABLE 2: Comparison between the different preservation solutions.

\begin{tabular}{lccc}
\hline Comparison & Superior & $\begin{array}{c}\text { Human/animal } \\
\text { study }\end{array}$ & Reference \\
\hline MK versus UW & MK & Porcine & {$[12]$} \\
MK versus UW & MK & Human & $\begin{array}{c}{[41] \text { (in }} \\
\text { discussion) }\end{array}$ \\
MK versus ET-K & MK & Rat & {$[12]$} \\
MK versus & MK & Porcine & {$[43]$} \\
M-HTK & MK & Human & {$[41]$} \\
MK versus HNC &
\end{tabular}

UW: University of Wisconsin solution;MK: modified ET-Kyoto solution (ET-Kyoto solution with ulinastatin); ET-K: ET-Kyoto solution; M-HTK: modified histidine-tryptophan-ketoglutarate solution (HTK solution with ulinastatin); HNC: Celsior solution with HES and nafamostat mesilate.

\section{Trypsin Inhibitors in Preservation Solution}

Trypsin from pancreatic acinar cells destroys islets. Previous study has shown that trypsin inhibition by Pefabloc during human pancreas digestion improves islet yield and reduces the fraction of embedded (trapped) islets [64], thus suggesting that trypsin may degrade the ductules and thus reduce the delivery of collagenase solution to tissue around the islets. We previously reported that pancreas
TABle 3: Trypsin inhibitors in ET-Kyoto solution.

\begin{tabular}{lcccc}
\hline $\begin{array}{l}\text { Trypsin } \\
\text { inhibitors }\end{array}$ & Trypsin & $\begin{array}{c}\text { Isle yield } \\
\text { versus } \\
\text { ulinastatin }\end{array}$ & $\begin{array}{c}\text { Viability } \\
\text { versus } \\
\text { ulinastatin }\end{array}$ & $\begin{array}{c}\text { SI* } \\
\text { versus } \\
\text { ulinastatin }\end{array}$ \\
\hline $\begin{array}{l}\text { Ulinastatin } \\
\text { Pefabloc }\end{array}$ & ++ & - & - & - \\
$\begin{array}{l}\text { Gabexate } \\
\text { mesilate }\end{array}$ & +++ & n.s. & Lower & Lower \\
$\begin{array}{l}\text { Nafamostat } \\
\text { mesilate }\end{array}$ & ++++ & n.s. & Lower & n.s. \\
${ }^{*}$ Stimulation index; n.s.: not significant. & &
\end{tabular}

preservation using MK solution including ulinastatin, which eliminated trypsin activity during pancreas preservation, was superior to that using ET-Kyoto solution without the trypsin inhibitor in a rat model [12]. Furthermore, the advantages of MK solution are its trypsin inhibition and less collagenase inhibition in human and porcine islet isolation $[12,47]$. Therefore, we compared ulinastatin with other trypsin inhibitors, including Pefabloc, gabexate mesilate, and nafamostat mesilate, in preservation solution for porcine islet isolation $[62,63]$. Trypsin inhibition is greater in ETKyoto with gabexate mesilate (GK) solution and ET-Kyoto with nafamostat mesilate (NK) solution than in MK solution. The islet yield before purification was higher in the MK group than in the ET-Kyoto with Pefabloc (PK) group. Viability was higher for the MK group than for either the GK group or the NK group. The stimulation index was higher for the MK group than for either the PK group or the GK group. These data suggest that MK solution was synthetically superior to the PK, GK, or NK solutions, although trypsin inhibition is greater in GK and NK solutions than in MK solution (Table 3) $[62,63]$, possibly due to differences of inhibitory effects of cytokines. Ulinastatin has been shown to inhibit not only trypsin activity but also the release of neutrophil elastase. It also downregulates transcription of TNF mRNA, the activation of endothelial cells, and the expression of ICAM-1 induced by endotoxin in vitro [6567]. The administration of ulinastatin has been shown to decrease ischemia-reperfusion injury [68] or attenuate the elevation in the concentrations of inflammatory cytokines and C-reactive protein, a marker of inflammation [69], in the transplanted small intestine.

Recently, the importance of tryptic-like activity (TLA) obtained from Clostridium histolyticum in collagenase NB1 with neutral protease for efficient islet isolation was demonstrated [70]. Enhancing TLA resulted in a significant reduction of recirculation time and incrementally increased human islet yield. The clostridial TLA and pancreatic trypsin seemed to be different in their specificity toward islet and nonislet pancreatic tissue because no detrimental effect on islet viability and integrity was detected on clostridial TLA. If trypsin inhibitors inhibit clostridial TLA as well as pancreatic trypsin, then they may inhibit pancreas digestion. This may explain the synthetic superiority of MK solution to PK, GK, or NK solutions, although trypsin inhibition is greater in GK and NK solutions than in MK solution (Figure 1(c)). 


\section{Two-Layer Method}

The two-layer preservation method (TLM), which uses the concept of normobaric oxygenation comprising a cold organ preservation solution (UW solution) with a perfluorochemical (PFC) oxygen carrier solution, with the pancreas being suspended between the two immiscible layers, has been utilized for many clinical trials of islet transplantation [71-74]. However, two recent large-scale studies showed no beneficial effect of TLM, compared with UW storage, on human islet isolation and transplantation $[75,76]$. We reevaluated the effect of TLM using three different groups: group 1: UW simple storage; group 2: TLM performed by multiorgan procurement teams (not specialists in islet isolation); group 3: TLM performed by specialists in islet isolation. There were no significant differences between group 1 and 2, whereas islet yields were significantly higher for group 3 compared with either groups 1 or 2 . Our data suggest that performance of TLM by experts could improve the outcome of islet isolation and transplantation [71].

On the other hand, Papas et al. showed that the oxygen penetration depth is about $1 \mathrm{~mm}$, suggesting that pancreas oxygenation is limited during preservation with the TLM [77]. In other words, their data suggest that the percentage of pancreas oxygenation by TLM depends on its thickness and the trimming of the pancreas before preservation by TLM is thus considered to be important for pancreas oxygenation.

\section{Conclusion}

ET-Kyoto with ulinastatin was the best combination for pancreas preservation in our studies. Since one of the advantages of MK solution is less collagenase inhibition in islet isolation, it is also suitable for ductal injection. Based on these data, we now use the in situ regional cooling system for DCD pancreata, the ductal injection of preservation solution, and pancreas preservation by $\mathrm{MK}$ solution during clinical islet isolation/transplantation. The in situ regional cooling system to DCD pancreata, ductal injection, and preservation by $\mathrm{MK}$ solution is therefore considered to be useful improvement that may help to increase organ utilization and thereby achieve good outcomes after islet transplantation.

\section{Conflict of Interest}

The author of this manuscript has no conflict of interests.

\section{References}

[1] A. M. J. Shapiro, J. R. T. Lakey, E. A. Ryan et al., "Islet transplantation in seven patients with type 1 diabetes mellitus using a glucocorticoid-free immunosuppressive regimen," The New England Journal of Medicine, vol. 343, no. 4, pp. 230-238, 2000.

[2] E. A. Ryan, J. R. T. Lakey, R. V. Rajotte et al., "Clinical outcomes and insulin secretion after islet transplantation with the edmonton protocol," Diabetes, vol. 50, no. 4, pp. 710-719, 2001.
[3] J. F. Markmann, S. Deng, N. M. Desai et al., "The use of non-heart-beating donors for isolated pancreatic islet transplantation," Transplantation, vol. 75, no. 9, pp. 14231429, 2003.

[4] H. A. Clayton, S. M. Swift, J. M. Turner, R. F. L. James, and P. R. F. Bell, "Non-heart-beating organ donors: a potential source of islets for transplantation," Transplantation, vol. 69, no. 10, pp. 2094-2098, 2000.

[5] H. Noguchi, Y. Yamada, T. Okitsu et al., "Secretory unit of islet in transplantation (SUIT) and engrafted islet rate (EIR) indexes are useful for evaluating single islet transplantation," Cell Transplantation, vol. 17, no. 1-2, pp. 121-128, 2008.

[6] H. Noguchi, Y. Iwanaga, T. Okitsu, H. Nagata, Y. Yonekawa, and S. Matsumoto, "Evaluation of islet transplantation from non-heart beating donors," American Journal of Transplantation, vol. 6, no. 10, pp. 2476-2482, 2006.

[7] B. J. Hering, R. Kandaswamy, J. D. Ansite et al., "Single-donor, marginal-dose islet transplantation in patients with type 1 diabetes," Journal of the American Medical Association, vol. 293, no. 7, pp. 830-835, 2005.

[8] B. J. Hering, R. Kandaswamy, J. V. Harmon et al., "Transplantation of cultured islets from two-layer preserved pancreases in type 1 diabetes with anti-CD3 antibody," American Journal of Transplantation, vol. 4, no. 3, pp. 390-401, 2004.

[9] B. J. Hering, I. Matsumoto, T. Sawada et al., "Impact of twolayer pancreas preservation on islet isolation and transplantation," Transplantation, vol. 74, no. 12, pp. 1813-1816, 2002.

[10] S. Matsumoto, M. Takita, D. Chaussabel et al., "Improving efficacy of clinical islet transplantation with iodixanol based islet purification, thymoglobulin induction and blockage of IL-1-beta and TNF-alpha," Cell Transplantation. In press.

[11] S. Matsumoto, T. Okitsu, Y. Iwanaga et al., "Insulin independence after living-donor distal pancreatectomy and islet allotransplantation," Lancet, vol. 365, no. 9471, pp. 16421644, 2005.

[12] H. Noguchi, M. Ueda, Y. Nakai et al., "Modified two-layer preservation method (M-Kyoto/PFC) improves islet yields in islet isolation," American Journal of Transplantation, vol. 6, no. 3, pp. 496-504, 2006.

[13] H. Noguchi, M. F. Levy, N. Kobayashi, and S. Matsumoto, "Pancreas preservation by the two-layer method: does it have a beneficial effect compared with simple preservation in University of Wisconsin solution?" Cell Transplantation, vol. 18, no. 5-6, pp. 497-503, 2009.

[14] H. Noguchi, "Pancreatic islet transplantation," World Journal of Gastrointestinal Surgery, vol. 1, no. 1, pp. 16-20, 2009.

[15] H. Noguchi, T. Ikemoto, B. Naziruddin et al., "Iodixanolcontrolled density gradient during islet purification improves recovery rate in human islet isolation," Transplantation, vol. 87, no. 11, pp. 1629-1635, 2009.

[16] H. Noguchi, S. Matsumoto, N. Onaca et al., "Ductal injection of JNK inhibitors before pancreas preservation prevents islet apoptosis and improves islet graft function," Human Gene Therapy, vol. 20, no. 1, pp. 73-85, 2009.

[17] H. Noguchi, B. Naziruddin, M. Shimoda et al., "A combined continuous density/osmolality gradient for supplemental purification of human islets," Cell Medicine. In press.

[18] H. Noguchi, Y. Nakai, S. Matsumoto et al., "Cell permeable peptide of JNK inhibitor prevents islet apoptosis immediately after isolation and improves islet graft function," American Journal of Transplantation, vol. 5, no. 8, pp. 1848-1855, 2005.

[19] H. Noguchi, Y. Nakai, M. Ueda et al., "Activation of c-Jun NH2-terminal kinase (JNK) pathway during islet transplantation and prevention of islet graft loss by intraportal injection 
of JNK inhibitor," Diabetologia, vol. 50, no. 3, pp. 612-619, 2007.

[20] H. Noguchi, B. Naziruddin, A. Jackson et al., "Lowtemperature preservation of isolated islets is superior to conventional islet culture before islet transplantation," Transplantation, vol. 89, no. 1, pp. 47-54, 2010.

[21] H. Noguchi, "Cell-permeable peptide inhibitor of c-Jun NH2-terminal kinase for the treatment of diabetes," Current Bioactive Compounds, vol. 6, no. 1, pp. 23-30, 2010.

[22] H. Noguchi, M. Matsushita, T. Okitsu et al., "A new cellpermeable peptide allows successful allogeneic islet transplantation in mice," Nature Medicine, vol. 10, no. 3, pp. 305-309, 2004.

[23] J. R. T. Lakey, G. L. Warnock, R. V. Rajotte et al., "Variables in organ donors that affect the recovery of human islets of Langerhans," Transplantation, vol. 61, no. 7, pp. 1047-1053, 1996.

[24] D. Brandhorst, B. J. Hering, H. Brandhorst, K. Federlin, and R. G. Bretzel, "Influence of donor data and organ procurement on human islet isolation," Transplantation Proceedings, vol. 26, no. 2, pp. 592-593, 1994.

[25] P. Fiedor, E. R. Goodman, R. S. Sung, J. Czerwiński, W. Rowiński, and M. A. Hardy, "The effect of clinical and biochemical donor parameters on pancreatic islet isolation yield from cadaveric organ donors," Annals of Transplantation, vol. 1, no. 1, pp. 59-62, 1996.

[26] Y. Zeng, M. A. Torre, T. Karrison, and J. R. Thistlethwaite, "The correlation between donor characteristics and the success of human islet isolation," Transplantation, vol. 57, no. 6, pp. 954-958, 1994.

[27] J. F. Markmann, S. Deng, N. M. Desai et al., "The use of non-heart-beating donors for isolated pancreatic islet transplantation," Transplantation, vol. 75, no. 9, pp. 14231429, 2003.

[28] H. A. Clayton, S. M. Swift, J. M. Turner, R. F. L. James, and P. R. F. Bell, "Non-heart-beating organ donors: a potential source of islets for transplantation," Transplantation, vol. 69, no. 10, pp. 2094-2098, 2000.

[29] H. Nagata, S. Matsumoto, T. Okitsu et al., "Procurement of the human pancreas for pancreatic islet transplantation from marginal cadaver donors," Transplantation, vol. 82, no. 3, pp. 327-331, 2006.

[30] M. Kato, K. Mizutani, R. Hattori et al., "In situ renal cooling for kidney transplantation from non-heart-beating donors," Transplantation Proceedings, vol. 32, no. 7, pp. 1608-1610, 2000.

[31] Y. Yonekawa, S. Matsumoto, T. Okitsu et al., "Effective islet isolation method with extremely high islet yields from adult pigs," Cell Transplantation, vol. 14, no. 10, pp. 757-762, 2005.

[32] J. J. O’Neil, J. P. Stegemann, D. T. Nicholson, K. A. Gagnon, B. A. Solomon, and C. J. P. Mullon, "The isolation and function of porcine islets from market weight pigs," Cell Transplantation, vol. 10, no. 3, pp. 235-246, 2001.

[33] C. Ricordi, P. E. Lacy, E. H. Finke, B. J. Olack, and D. W. Scharp, "Automated method for isolation of human pancreatic islets,” Diabetes, vol. 37, no. 4, pp. 413-420, 1988.

[34] S. R. Munn, D. B. Kaufman, M. J. Field, A. B. Viste, and D. E. R. Sutherland, "Cold-storage preservation of the canine and rat pancreas prior to islet isolation," Transplantation, vol. 47, no. 1, pp. 28-31, 1989.

[35] H. Noguchi, M. Ueda, S. Hayashi et al., "Ductal injection of preservation solution increases islet yields in islet isolation and improves islet graft function," Cell Transplantation, vol. 17, no. $1-2$, pp. 69-81, 2008.
[36] T. Sawada, I. Matsumoto, M. Nakano, N. Kirchhof, D. E. R. Sutherland, and B. J. Hering, "Improved islet yield and function with ductal injection of University of Wisconsin solution before pancreas preservation," Transplantation, vol. 5, no. 12, pp. 1965-1969, 2003.

[37] T. Tojimbara, W. N. Wicomb, R. Garcia-Kennedy et al., "Liver transplantation from non-heart beating donors in rats: influence of viscosity and temperature of initial flushing solutions on graft function," Liver Transplantation and Surgery, vol. 3, no. 1, pp. 39-45, 1997.

[38] G. S. Robertson, D. Chadwick, S. Thirdborough et al., "Human islet isolation-a prospective randomized comparison ofpancreatic vascular perfusion with hyperosmolar citrate or University ofWisconsin solution," Transplantation, vol. 56, no. 3, pp. 550-553, 1993.

[39] H. H. Contractor, P. R. V. Johnson, D. R. Chadwick, G. S. M. Robertson, and N. J. M. London, "The effect of UW solution and its components on the collagenase digestion of human and porcine pancreas," Cell Transplantation, vol. 4, no. 6, pp. 615619, 1995.

[40] M. Omasa, S. Hasegawa, T. Bando et al., "Application of ETKyoto solution in clinical lung transplantation," Annals of Thoracic Surgery, vol. 77, no. 1, pp. 338-339, 2004.

[41] F. Chen, T. Fukuse, S. Hasegawa et al., "Effective application of ET-Kyoto solution for clinical lung transplantation," Transplantation Proceedings, vol. 36, no. 9, pp. 2812-2815, 2004.

[42] S. F. Wu, Y. Suzuki, A. K. Kitahara, H. Wada, and Y. Nishimura, "Skin flap storage with intracellular and extracellular solutions containing trehalose," Annals of Plastic Surgery, vol. 43, no. 3, pp. 289-294, 1999.

[43] R. Troisi, D. Meester, C. Van Den Broecke et al., "Functional and structural integrity of porcine pancreatic graftssubjected to a period of warm ischemia and cold preservation withhistidine-tryptophan-ketoglutarate (custodiol) or University of Wisconsinsolution," Transplantation, vol. 75, no. 11, pp. 1793-1799, 2003.

[44] F. O. Belzer and J. H. Southard, "Organ preservation and transplantation," Progress in Clinical and Biological Research, vol. 224, pp. 291-303, 1986.

[45] D. R. Chadwick, G. S. M. Robertson, H. H. Contractor et al., "Storage of pancreatic digest before islet purification: the influence of colloids and the sodium to potassium ratio in University of Wisconsin-based preservation solutions," Transplantation, vol. 58, no. 1, pp. 99-104, 1994.

[46] S. Fujimoto, E. R. I. Mukai, Y. Hamamoto et al., "Prior exposure to high glucose augments depolarization-induced insulin release by mitigating the decline of ATP level in rat islets," Endocrinology, vol. 143, no. 1, pp. 213-221, 2002.

[47] H. Noguchi, B. Naziruddin, N. Onaca et al., "Comparison of modified Celsior solution and M-Kyoto solution for pancreas preservation in human islet isolation," Cell Transplantation, vol. 19, no. 6-7, pp. 751-758, 2010.

[48] H. J. Bretschneider, "Myocardial protection," The Thoracic and Cardiovascular Surgeon, vol. 28, no. 5, pp. 295-302, 1980.

[49] J. Erhard, R. Lange, R. Scherer et al., "Comparison of histidinetryptophan-ketoglutarate (HTK) solution versus University of Wisconsin (UW) solution for organ preservation in human liver transplantation. A prospective, randomized study," Transplant International, vol. 7, no. 3, pp. 177-181, 1994.

[50] U. J. Hesse, R. Troisi, B. Jacobs et al., "Cold preservation of the porcine pancreas with histidine-tryptophan- ketoglutarate solution," Transplantation, vol. 66, no. 9, pp. 1137-1141, 1998.

[51] U. Leonhardt, A. Tytko, B. Exner et al., "The effect of different solutions for organ preservation of immediate postischemic 
pancreatic function in vitro," Transplantation, vol. 55, no. 1, pp. 11-14, 1993.

[52] S. Potdar, S. Malek, B. Eghtesad et al., "Initial experience using histidine-tryptophan-ketoglutarate solution in clinical pancreas transplantation," Clinical Transplantation, vol. 18, no. 6, pp. 661-665, 2004.

[53] M. J. Englesbe, A. Moyer, D. Y. Kim et al., "Early pancreas transplant outcomes with histidine-tryptophan-ketoglutarate preservation: a multicenter study," Transplantation, vol. 82, no. 1, pp. 136-139, 2006.

[54] J. A. Fridell, A. Agarwal, M. L. Milgrom, W. C. Goggins, P. Murdock, and M. D. Pescovitz, "Comparison of histidinetryptophan-ketoglutarate solution and University of Wisconsin solution for organ preservation in clinical pancreas transplantation," Transplantation, vol. 77, no. 8, pp. 13041306, 2004.

[55] H. Noguchi, M. Ueda, S. Hayashi et al., "Comparison of M-Kyoto solution and histidine-tryptophan-ketoglutarate solution with a trypsin inhibitor for pancreas preservation in islet transplantation," Transplantation, vol. 84, no. 5, pp. 655658, 2007.

[56] J. Caballero-Corbalán, H. Brandhorst, H. Malm et al., "Using HTK for prolonged pancreas preservation prior to human islet isolation," The Journal of Surgical Research. In press.

[57] P. Menasché, J. L. Termignon, F. Pradier et al., "Experimental evaluation Celsior, a new heart preservation solution," European Journal of Cardio-Thoracic Surgery, vol. 8, no. 4, pp. 207213, 1994.

[58] R. F. Roberts, G. P. Nishanian, J. N. Carey, Y. Sakamaki, V. A. Starnes, and M. L. Barr, "A comparison of the new preservation solution Celsior to Euro-Collins and University of Wisconsin solutions in lung reperfusion injury," Transplantation, vol. 67, no. 1, pp. 152-155, 1999.

[59] A. Cavallari, U. Cillo, B. Nardo et al., "A multicenter pilotprospective study comparing Celsior and University of Wisconsin preservingsolutions for use in liver transplantation," Liver Transplantation, vol. 9, no. 8, pp. 814-821, 2003.

[60] A. Faenza, F. Catena, B. Nardo et al., "Kidney preservationwith university of Wisconsin and Celsior solution: a prospective multicenterrandomized study," Transplantation, vol. 72, no. 7, pp. 1274-1277, 2001.

[61] T. Hubert, V. Gmyr, L. Arnalsteen et al., "Influence of preservation solution on human islet isolation outcome," Transplantation, vol. 83, no. 3, pp. 270-276, 2007.

[62] H. Noguchi, M. Ueda, S. Hayashi et al., "Comparison of trypsin inhibitors in preservation solution for islet isolation," Cell Transplantation, vol. 18, no. 5-6, pp. 541-547, 2009.

[63] H. Noguchi, B. Naziruddin, A. Jackson et al., "Comparison of ulinastatin, gabexatemesilate, and nafamostatmesilate in preservation solution for islet isolation," Cell Transplantation. In press.

[64] J. R. T. Lakey, L. M. H. Helms, T. Kin et al., "Serine-protease inhibition during islet isolation increases islet yield from human pancreases with prolonged ischemia," Transplantation, vol. 72, no. 4, pp. 565-570, 2001.

[65] S. Aosasa, S. Ono, H. Mochizuki, H. Tsujimoto, C. Ueno, and A. Matsumoto, "Mechanism of the inhibitory effect of protease inhibitor on tumor necrosis factor $\alpha$ production of monocytes," Shock, vol. 15, no. 2, pp. 101-105, 2001.

[66] S. Aosasa, S. Ono, S. Seki et al., "Inhibitory effect of protease inhibitor on endothelial cell activation," Journal of Surgical Research, vol. 80, no. 2, pp. 182-187, 1998.

[67] K. Nakatani, S. Takeshita, H. Tsujimoto, Y. Kawamura, and I. Sekine, "Inhibitory effect of serine protease inhibitors on neutrophil-mediated endothelial cell injury," Journal of Leukocyte Biology, vol. 69, no. 2, pp. 241-247, 2001.

[68] J. L. Sun, X. Q. Zhang, Z. G. Yu et al., "Effects of ulinastatin on postoperative systemic inflammatory response of recipients of rat small bowel transplantation," Transplantation Proceedings, vol. 38, no. 6, pp. 1803-1804, 2006.

[69] X. Q. Zhang, J. L. Sun, Y. J. Chen, R. Ma, X. H. Fan, and J. Z. Sun, "Amelioration of ischemia-reperfusion injury of transplanted small intestine by ulinastatin: effects on accumulation and adhesion of neutrophil," Transplantation Proceedings, vol. 37, no. 10, pp. 4464-4466, 2005.

[70] H. Brandhorst, A. Friberg, H. H. Andersson et al., "The importance of tryptic-like activity in purified enzyme blends for efficient islet isolation," Transplantation, vol. 87, no. 3, pp. 370-375, 2009.

[71] H. Noguchi, M. F. Levy, N. Kobayashi, and S. Matsumoto, "Pancreas preservation by the two-layer method: does it have a beneficial effect compared with simple preservation in University of Wisconsin solution?" Cell Transplantation, vol. 18, no. 5-6, pp. 497-503, 2009.

[72] T. Tsujimura, Y. Kuroda, T. Kin et al., "Human islet transplantation from pancreases with prolonged cold ischemia using additional preservation by the two-layer (UW solution/perfluorochemical) cold-storage method," Transplantation, vol. 74, no. 12, pp. 1687-1691, 2002.

[73] C. Ricordi, C. Fraker, J. Szust et al., "Improved human islet isolation outcome from marginal donors following addition of oxygenated perfluorocarbon to the cold-storage solution," Transplantation, vol. 75, no. 9, pp. 1524-1527, 2003.

[74] B. J. Hering, R. Kandaswamy, J. V. Harmon et al., "Transplantation of cultured islets from two-layer preserved pancreases in type 1 diabetes with anti-CD3 antibody," American Journal of Transplantation, vol. 4, no. 3, pp. 390-401, 2004.

[75] J. Caballero-Corbalán, T. Eich, T. Lundgren et al., "No beneficial effect of two-layer storage compared with UW-storage on human islet isolation and transplantation," Transplantation, vol. 84, no. 7, pp. 864-869, 2007.

[76] T. Kin, M. Mirbolooki, P. Salehi et al., "Islet isolation and transplantation outcomes of pancreas preserved with University of Wisconsin solution versus two-layer method using preoxygenated perfluorocarbon," Transplantation, vol. 82, no. 10, pp. 1286-1290, 2006.

[77] K. K. Papas, B. J. Hering, L. Gunther, M. J. Rappel, C. K. Colton, and E. S. Avgoustiniatos, "Pancreas oxygenation is limited during preservation with the two-layer method," Transplantation Proceedings, vol. 37, no. 8, pp. 3501-3504, 2005. 


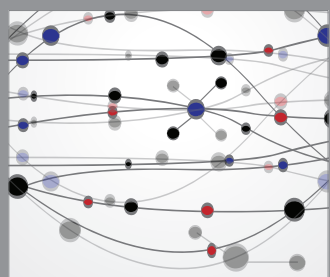

The Scientific World Journal
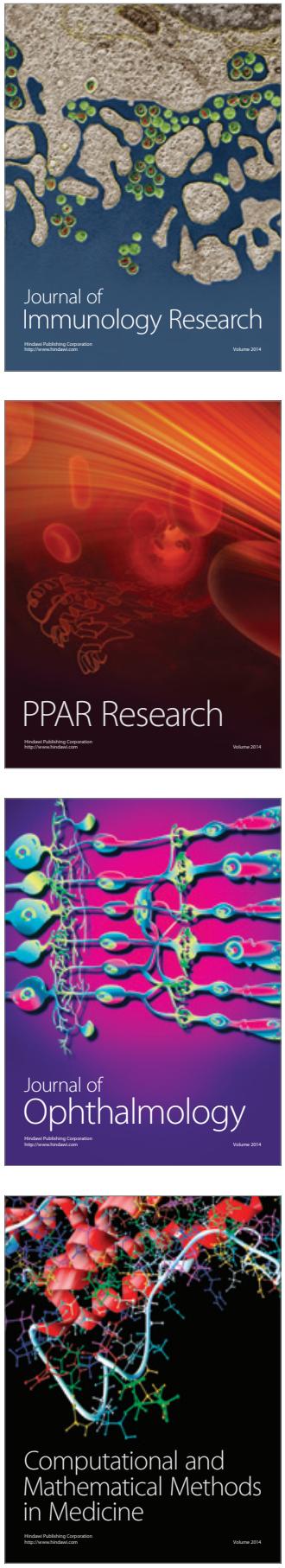

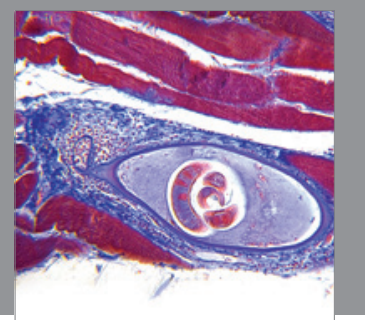

Gastroenterology

Research and Practice
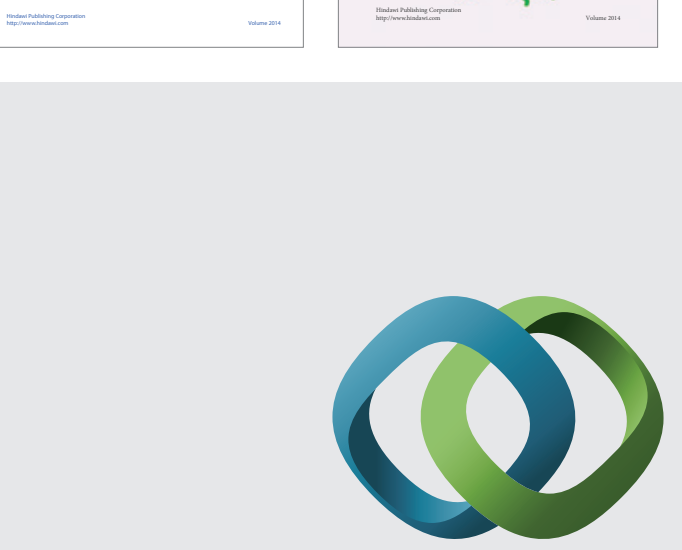

\section{Hindawi}

Submit your manuscripts at

http://www.hindawi.com
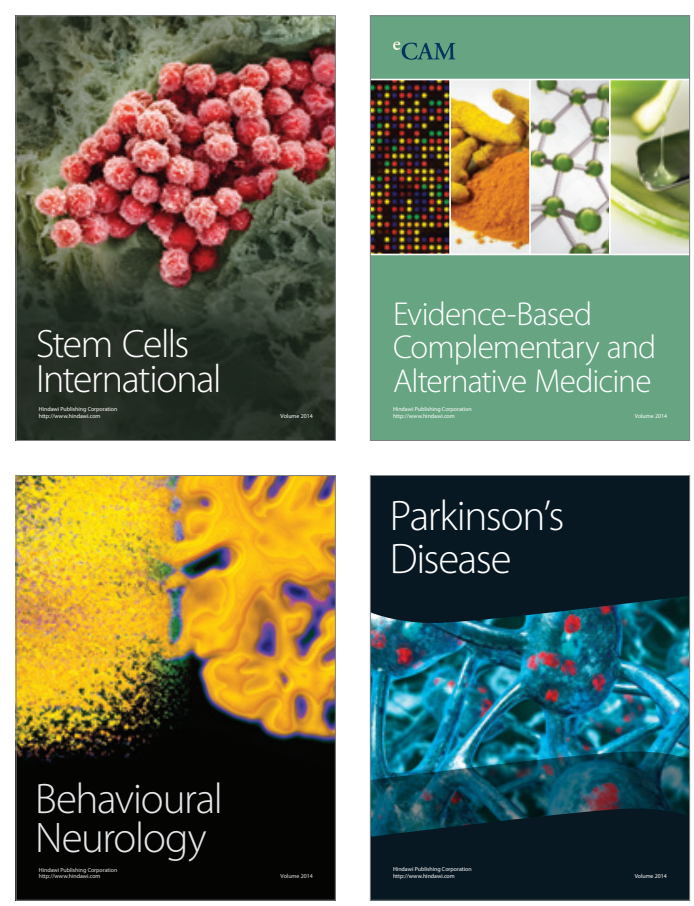

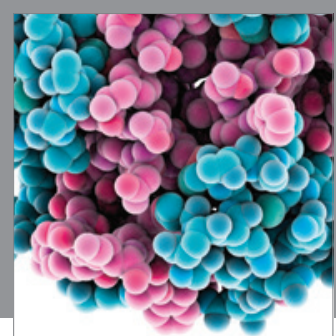

Journal of
Diabetes Research

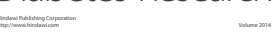

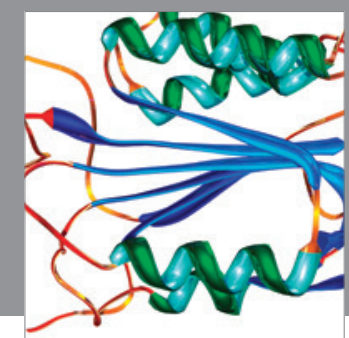

Disease Markers
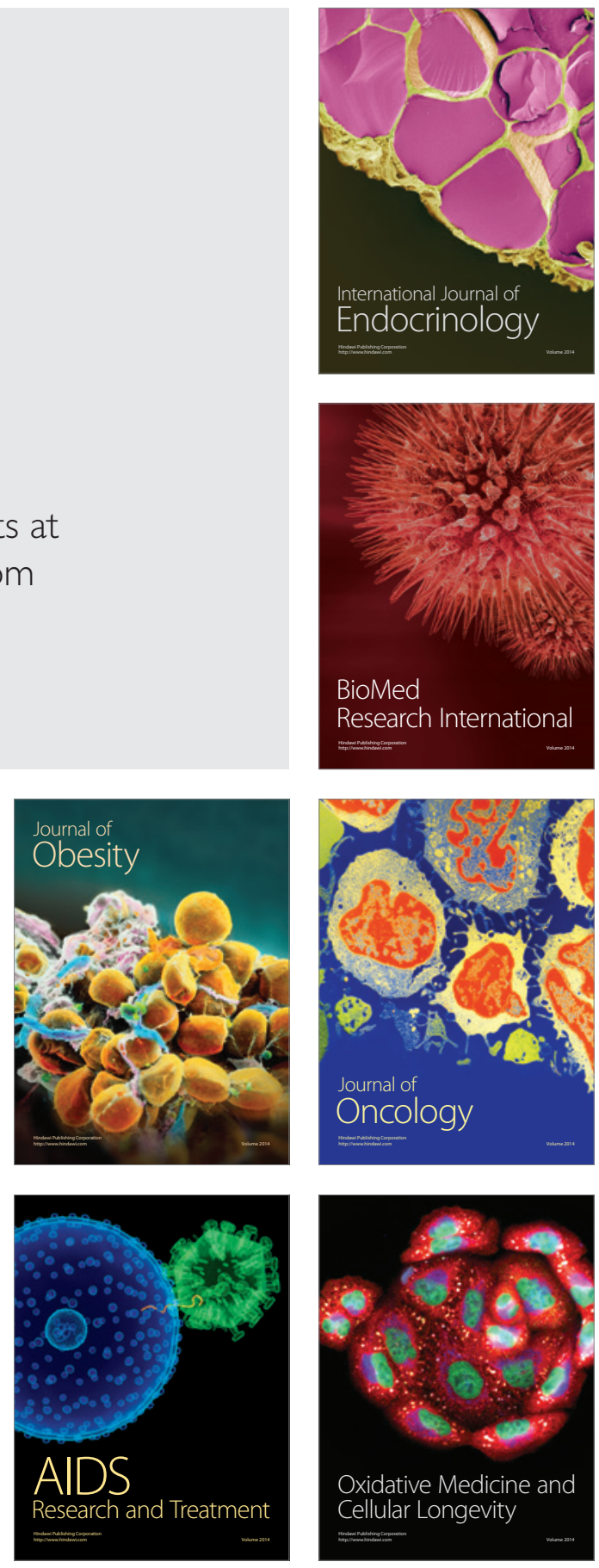